\title{
EDITORIAL
}

\section{Awesome Chemistry from the End of the World}

The second number of this first volume of Science Reviews from the End of the World, is dedicated to chemistry, more specifically, charge transfer processes in transition metal complexes. While Profs. Katz and Wolcan discuss the subject focused on inorganic complexes (attached to polymers in the case of Wolcan), Profs. Murgida and Brondino et al dedicate their reviews to metalloproteins. Therefore, we could say that the areas represented in this issue are inorganic, organometallic and bioinorganic chemistry.

The four featured researchers and their groups are from different cities of Argentina, distributed throughout the country: Buenos Aires, La Plata, Santa Fe and Tucumán. They are world leaders in their fields and regularly publish their research in first-class journals. As an editor, I am not only pleased but also thankful that they have accepted to participate in this journal, which is not only just starting, but also edited at the End of the World. We decided to add this subtitle to the journal, at first because of the famous lighthouse located at the very south of Argentina, referred to by Jules Verne in his novel The Lighthouse at the End of the World. However, this is not the only reason for using this reference - since our country is the southernmost country in South of America, we are often quite isolated from the rest of the world. Not only because of the distances that we have to travel - especially nowadays, with airplanes that make travelling a fast and easy journey - but also due to the high costs associated with that. In general, the grants provided by the State are quite tiny, a tenth or even a hundredth of the amounts granted in Europe, USA and other first-world countries. Nevertheless, our works are judged in the first-class journals by applying the same rules and guidelines applied to any submitted manuscript, which makes the works presented in this "editorial anomaly" even more attractive and unique.

Fabio Doctorovich Editor

\section{Bio}

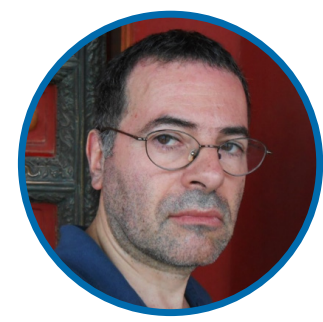

\section{Fabio Doctorovich}

Full Professor at the University of Buenos Aires (UBA, Argentina) and Researcher at CONICET, he obtained his $\mathrm{PhD}$ in Organic Chemistry from UBA in 1990 . He was a postdoctoral fellow at the Georgia Institute of Technology working with Prof. E.C. Ashby and K. Barefield, first on single electron transfer, and afterwards on chemical reactions taking place in nuclear waste tanks. Back in Argentina, he started to work on nitric oxide (NO), including organic nitrosocompounds, inorganic iron, rhodium, ruthenium and iridium nitrosyl complexes, and reactivity of metalloporphyrins and pincer complexes towards HNO. He also worked on CO complexes, catalytic reactions, and other topics. Nowadays his main research focus is on reactions involving HNO. Prof. Doctorovich has published over 120 works in international journals such as Accounts of Chemical Research, Journal of the American Chemical Society, Inorganic Chemistry, Nature Communications, as well as the book The Chemistry and Biology of Nitroxyl (HNO) published at Elsevier, 2016. He has supervised $15 \mathrm{Ph}$. D. students. In 2011 he received the Guggenheim Fellowship and in 2016 the Innovar Prize. 